\title{
The Impact of Activity Sequencing on the Differences between ELT Methods: A Critical Analysis of Sample Units
}

\author{
Raguel Criado Sánchez \\ Universidad de Murcia
}

Received: 12 July 2009 / Accepted: 20 November 2009

ISSN: 1697-7467

\begin{abstract}
One of the methodological variables frequently forgotten by most ELT methods is activity sequencing. However, this is not a secondary variable and it should be intrinsically related to the cognitive built-in process governing knowledge acquisition. Consequently, activity sequencing fully affects the pedagogically based organisation of the teaching materials and the cognitive processes of language acquisition. The aim of this paper is to perform an analysis of the activity sequencing in three different textbooks representative of three main methods in the history of ELT: the Direct Method, the Audiolingual Method and the Communicative Method. The analysis will be undertaken from pedagogical and cognitive perspectives. The results will illustrate a) the degree of agreement or non-agreement detected in each method and textbook; b) that the activity sequencing variable is crucial to determine the nature of such differences or similarities. Since the activity sequencing is similar across the three textbooks, it could be assumed that methodological differences may be of less consequence than usually considered. Key words: ELT, activity sequencing, cognitive sequencing, PPP.
\end{abstract}

Secuenciación de actividades y su efecto diferenciador en los métodos para la enseñanza del inglés como lengua extranjera: análisis crítico de muestras

RESUMEN: Una de las variables que han sido preteridas con frecuencia por casi todos los métodos para la enseñanza del inglés como lengua extranjera es la secuenciación de actividades. Sin embargo, la secuenciación de actividades no es una variable secundaria, ya que debería estar estrechamente relacionada con los procesos cognitivos que rigen la adquisición de conocimientos; por tanto, afecta en gran medida a la organización de los materiales docentes. El objetivo de este trabajo es analizar la secuenciación de las actividades en tres manuales diferentes representativos de tres importantes métodos en la enseñanza del inglés como lengua extranjera: el Método Directo, el Método Audiolingual y el Método Comunicativo. El análisis se realizará desde dos perspectivas: pedagógica y cognitiva. Los resultados ilustrarán las semejanzas o diferencias en cada método y manual; además, mostrarán que la variable de la secuenciación de actividades es crucial para determinar tales semejanzas y diferencias. Dado que en este caso dicha variable es similar en los tres manuales, se puede asumir que las diferencias metodológicas tal vez sean menos importantes de lo que se suele considerar.

Palabras clave: enseñanza del inglés como lengua extranjera, secuenciación de actividades, secuenciación cognitiva, PPP. 


\section{INTRODUCTION}

My viewpoint in this paper is rooted in the following belief: a method for learning languages is made up of many elements and each one of them may be important for achieving success. All methods in the history of language teaching (Kelly, 1969; Sánchez, 1997, 2009; Howatt, 2004) have emphasised different and specific aspects (the cognitive potential, oral practice, pattern practice, communicative activities, etc.). I firmly believe that one of the aspects that may affect teaching is activity sequencing, since it is intrinsically related to the cognitive sequence(s) of learning processes carried out by all human beings in order to acquire and consolidate their knowledge. Consequently, activity sequencing will be more efficient if it adjusts to the built-in sequence(s) involved in knowledge acquisition, which in turn will add to the global improvement of EFL (English as a Foreign Language) learning and teaching.

In this work, I will study the activity sequencing patterns in three well-known ELT (English Language Teaching) coursebooks representative of different periods and methods from both a pedagogical and a cognitive perspective: the Direct Method, the Situational Language Teaching Method and the Communicative Method. This analysis will allow us to identify the extent to which past practices deviate from contemporary practices regarding activity sequencing, which will constitute a first step for improvements in ELT and research on this essential aspect.

\section{What is 'SEQUENCING'}

What is understood by sequencing in general? Two dictionaries were randomly selected to provide a response.

The New Shorter Oxford English Dictionary (1997) directs the reader to the entry "sequence" when introducing "sequencing". As a verb, sequence is defined as "arrange in a definite order". As a noun, it is explained as:

The action or condition of following or succeeding; the following of one thing after another; an instance of this. The order in which things succeed one another. A continuous series of things, a succession; a set of related things arranged in a certain order.

A very similar description can be found in the Merriam-Webster Online. This source, similar to the New Shorter Oxford Dictionary, leads the user to "sequence" when searching for, "sequencing". As a verb, sequence is defined as, "to arrange in a sequence". As a noun, it is described as, "a continuous or connected series" and as, "order of succession".

Therefore, according to those standard dictionaries, the main recurrent features of sequencing and sequence are "ordering" and "succession". Such features can be extrapolated to the field of Applied Linguistics, specifically to Foreign Language Teaching. Within this area, we can observe two different meanings that share the semantic components "ordering" and "succession": the sequencing of the content to be learned and the sequencing of the activities in a textbook lesson. I concentrate here on the ordering of activities alone.

Sequencing has not received much attention among scholars. As Sánchez (2004: 178) suggests, sequences of activities reveal a specific relationship between the activities involved, 
which leads towards particular patterns of work and organisational procedures in the classroom. Accordingly, sequencing is directly related to the following areas:

a) The methodology followed by the textbook or the teacher and the sequencing principles that it advocates (as revealed by the sequencing structure);

b) the psychological sequence of actions carried out by all human beings and each individual person in order to acquire and consolidate their knowledge;

c) the variety of the teaching procedures, which should under normal circumstances foster the students' motivation;

d) the degree of complexity encapsulated by the development of an activity.

As can be seen, these four areas reflect the remarkable significance of sequencing, which becomes a pedagogical tool whose effects on language learning warrant attention and further study. Without neglecting the great importance of c) and d) in language learning, in this work I will focus on aspects a) and b) owing to limitations of space.

\section{ACTIVITY SEQUenCING: MODELS OF ANALYSIS, DESCRIPTION OF METHODS AND TEXTBOOKS}

The nature and extension of this paper includes important restrictions in the analysis of sequencing, its models, the rationale behind, and the number of samples analysed (see Criado, 2008: chapter 5, for further information). Before proceeding in section 4 with the analysis of the units selected, I will outline the models of analysis and both the methods and textbooks.

\subsection{Models of analysis: the PPP and Anderson's model of cognitive learning}

I will study activity sequencing from two perspectives: pedagogical and psychological. Regarding the former, the 'Presentation (P1)-Practice (P2)-Production (P3) model of activity' (PPP) will be considered. As to the latter, I will follow Anderson's model of skill learning, that is, Adaptive Control of Thought (ACT) or its latest ACT-R version (Adaptive Control of Thought-Rational) (Anderson, 1982, 1987, 2005; Anderson and Lebiere, 1998; Anderson et al., 2004).

The PPP illustrates a well established procedure in most classrooms. P1 is first and allows for the presentation of the new language or content to be learned. P2 is devoted to practice. It is aimed at consolidating such new language through rehearsal. P3 fully enters the production stage: after the practice phase, students should demonstrate their skills in using the language autonomously. This model can be associated with a traditional procedure habitual in the classroom and inherited by teachers without even questioning its validity and efficacy. No doubt, this tradition is closely connected to daily practice and common sense leading to action and practical work, but it is not derived from experimental findings. Still, the model is not to be necessarily linked to failure in the learning process as some critics maintain (Lewis, 1996; Skehan, 1998; D. Willis and J. Willis, 2007, etc.). Mostly the deductive approach underlies and supports this model, although inductive presentation can also be included in the first stage.

Anderson's model arises from psychological research and has been widely applied in SLA (O’Malley et al., 1987; Johnson, 1996, 2008; DeKeyser, 1998, 2007a, 2007b; DeKeyser and 
Sokalski, 1996). DeKeyser (1998: 48) states that "Anderson's is the most widely accepted model in the cognitive psychology of skill acquisition". Anderson attempts to describe the cognitive processes that take place in our brain while accessing, processing and storing knowledge. Moreover, Anderson's theory is more and more in line with neurological research regarding the way our neural network processes and stores input data, which will ultimately result in knowledge (Ullman, 2004). Also, Anderson's model is rooted in the two types of knowledge which are widely accepted by contemporary scholars regarding the manner in which knowledge is stored in our memory (Anderson, 1982, 1987, 2005; Anderson et al. 2004; Johnson, 1994, 1996, 2001; DeKeyser, 1998, 2007, among others): declarative and procedural knowledge henceforth $D E C$ and $P R O$ respectively. $D E C$ and $P R O$ are important in language learning and their presence or absence in the classroom will by necessity affect and condition the methodological action. $D E C$ is often defined as 'knowledge-that' and is complementary to $P R O$, or 'knowledgehow'. $D E C$ is, in terms of language, the knowledge we have about the underlying structures of the linguistic system. It is therefore conscious knowledge. PRO, on the other hand, is fully automatised and it does not require explicitly thinking about what one does. In language acquisition, to gain this stage of 'automatisation' means that one has reached a good command of the language.

Anderson's theory is particularly relevant regarding activity sequencing from the point of view of the order adults adjust to in the acquisition of $D E C$ and $P R O$ in formal contexts. Anderson (1982: 380-381, 2005: 281-282) states that DEC precedes $P R O$. This results in the cognitive sequence $D E C->P R O$, i.e. $D E C$ leads to $P R O$, which is later automatised through the three different phases (in this order) of cognitive elaboration, associative and autonomous. However, it should be observed that the $D E C->P R O$ sequence bears some restrictions as applied in 'natural' learning situations, i.e. native and non-formal L2 language learning (Johnson, 1996: 97-98, 2008: 106)).

$D E C \rightarrow P R O$ fully affects the cognitive pattern of language acquisition, which would account for this sequence in the ELT materials and would therefore claim a similar sequencing in the activities planned for the classroom. $D E C \rightarrow P R O$ as a learning sequence can easily be identified with the widely employed PPP foreign language teaching sequence. In teaching terms, and following Johnson (1996: 103, 2008: 276), the first P (P1) is mostly devoted to declarativisation while proceduralisation and full automatisation respectively correspond to the other two (P2 and P3). Also, very controlled and specific P2 such as sentence paraphrasing, translation, etc., can contribute to the solid development of declarative knowledge in long-term memory (DeKeyser, 1998: 58).

\subsection{Preliminary notes on the analysis and brief description of the methods and textbooks selected}

With the two previous perspectives in mind -pedagogical and cognitive- I will offer three examples to illustrate the structure and nature of sequencing regarding three well known and differentiated ELT methods: the Direct Method, the Situational Language Teaching Method and the Communicative Method. My goal will centre on discovering the structure of activity sequencing in a unit randomly selected from (i) Berlitz Method for Teaching Modern Languages. English Part. First Book (1931), (ii) L.G. Alexander's First Things First. An Integrated Course for Beginners. Student's Book (1967a) and (iii) C. Oxenden and C. Latham-Koenig's 
English File Upper Intermediate. Student's Book (2001). These three textbooks are targeted at adults and young adults. The first two manuals belong to the beginner level and the third textbook corresponds to the upper-intermediate level. I consider that the difference in levels is not an extraneous variable for my purpose in this paper, since cognitive sequencing does not necessarily depend on the level of the teaching materials or on their degree of difficulty. This will be shown later in the analysis.

For reliability purposes in the analysis, the units to be examined are located in the middle block of each coursebook, since it could be assumed that units placed in such a position are more representative of the overall methodology in each material. In this way, 'Travelling' lesson (number eight) was examined out of the whole seventeen lessons in the second part from Berlitz's book; teaching unit 36 out of the overall seventy-two units was selected in First Things First, and finally, file 3A (the seventh one out of the twenty-one files) was studied from English File Upper Intermediate. Appendix 2 offers the full two-page unit of First Things First, whilst Appendices 1 and 3 respectively include samples from Berlitz's selected unit (the first, fourth and fifth pages) and from that of English File Upper Intermediate (the first page). The reader is addressed to all these textbooks for the entire content of the above-mentioned units (see References).

In section 4, I will perform an analytical comparison of the activity sequencing patterns discerned in each coursebook to verify if and how such sequence implementations differ from the teaching and cognitive models outlined in each case above.

\subsubsection{Berlitz's Method}

Berlitz's name unwillingly came to be associated with the Direct Method, which emerged at the end of the $19^{\text {th }}$ century and which advocated natural learning; accordingly, it epitomises a strong reaction against the analytic and mother-tongue advocacy of the previous GrammarTranslation Method.

The First Book of Berlitz Method for Teaching Modern Languages. English Part is divided into two parts. The first part, which includes twelve lessons, is called 'Preparatory Lessons' or 'Object teaching'. As its name implies, it comprises the 'typical' classroom implementation from the Direct Method, i.e., use of realia, pictures, mime, etc. The second part, to which my selected unit belongs, is titled as 'Elementary Reading and Conversation (Teaching through context)' and consists of seventeen units of around five pages each. I decided to work with a unit from this second part as it deviated from the traditional objectteaching approach pursued in the Direct Method.

\subsubsection{The Situational Language Teaching Method: the European variety of the Audiolingual Method}

Structurally based methods became extremely popular in the classroom all over the world in the 1960 s and early $1970 \mathrm{~s}$. In some cases, their popularity reached the end of the $20^{\text {th }}$ century. Structurally based methods claimed a scientific basis for their action and principles and adapted fairly well to the PPP regarding activity sequencing in each unit or lesson.

I have opted here for a sample from the most representative European variety of the Audiolingual method, i.e. the Situational Language Teaching Method: First Things First, by 
L. G. Alexander (1967a). This is the first of the four-volume New Concept English series. First Things First is an excellent exponent of this method in the structure of the various sections of each unit, in the vocabulary control it submits to and in the transparent methodological action perceived throughout the activities throughout the lesson. According to the method to which it pertains, First Things First favours the inductive learning of patterns and vocabulary through drills supported by visuals, and it complies with the basic principle from natural, inductive methods that oral skills should precede written skills (Alexander, 1967b: xiii; Sánchez, 1997: 109; 2009: 53; Cook, 2001: 207-208; Richards and Rodgers, 2001: 58).

In terms of organisation, there are seventy-two teaching units in First Things First. Each of these units corresponds to two students' lessons. Thus, our selected unit 36 corresponds to students' lessons 71 and 72 (see Appendix 2). According to the Teacher's Book (Alexander, 1967b: xvii-xxiv), lessons consist of two parts, which include four and five activities respectively. The first part and page introduce a dialogue or text accompanied by pictures and comprise 'comprehension questions', a 'pattern drill' and an 'activity'. The second part and page presents of a set of structural exercises, which according to the Teacher's Book (Alexander, 1967b: xix-xxiv) encompass, in this order, a second 'pattern drill' exercise, a 'repetition drill', a third 'pattern drill', a fourth 'pattern drill' called 'exercise' and a 'dictation'. Except for the text and the drawings from the first part, on the one hand, and the textual chart, drawings and last pattern drill from the second part, on the other, the rest of the exercises are not printed in the Students' Book. In the following analysis all of the activities indicated in the Teacher's Book will be considered.

\subsubsection{The Communicative Method}

The third textbook, English File Upper Intermediate, represents the mainstream topicbased course within the modern and stereotypical 'weak' version of the Communicative Method ('Communicative Approach' in Howatt, 1984: 279). Among other characteristics, this 'weak' version stresses that students must use their communicative capacities in order to learn the language. Consequently, there is both a focus on form and a focus on meaning in a more levelled way than in the 'strong' version, where learners directly proceed to learn how to use the language by actually deploying their communicative capacities.

In terms of structure, English File Upper Intermediate is organised into seven five-page units called files, each of which contains three subfiles, thus totalling twenty-one files. All of these are devoted to the sub-skills (grammar, vocabulary and pronunciation) and the four skills (reading, listening, writing and speaking).

\section{The analysis of The ACTIVIty SEQUencing IN THE THREe Lessons}

\subsection{The Direct Method: Berlitz, M.D. (1931). Berlitz Method for Teaching Modern Languages. English Part. First Book}

\subsubsection{Topic and learning content of the unit}

The topic of this lesson is unmistakably revealed by its title: 'Travelling'. As to grammar, reviewing is appreciated regarding frequency adverbs, the superlative degree of adjectives, 
personal pronouns, demonstrative determiners, time expressions, and the modal verb "must". Modalised uses of "will" and "shall" which have not been previously studied in the textbook are also included. Names of countries, cities, location of nations and capitals, measurements and means of travelling constitute the vocabulary area. The skills practised are listening (to questions) and speaking (answering those questions).

\subsubsection{The activity sequencing pattern from a pedagogical perspective}

The lesson is divided into three parts: 'Oral Introduction' (pp. 57-58); 'Reading and Conversation' (pp. 58-60) and 'Exercises’ (pp. 60-61). Pages 57, 60 and 61 are included in Appendix 1.

The 'Oral Introduction' consists of a Teacher - Student conversation. This closely resembles one of the multiple drills identified by Lado for the Audiolingual Method (Lado, 1964: 100): question-and-answer exercise. Due to this format, the 'Oral Introduction' involves an amalgamation between P1 and P2. The teacher's utterances act as an inductive and implicit P1 for the introduction of the new forms (grammar and vocabulary); the students' attention is not explicitly drawn to such forms but these are to be inductively inferred from the teacher's utterances, which also constitute aural receptive practice (P2). The students' answers involve practice of the new language elements, both grammar and vocabulary (P2):

London is the capital of England. What is the name

of the capital of France? Of Germany? (lines 1-2)

The next part, or 'Reading and Conversation', represents a contrived dialogue between two people that is read aloud by the teacher and includes related content from the previous part. On the one hand, it comprises an inductive and partially implicit ${ }^{1} \mathrm{P} 1$ for the language forms studied; on the other, it also allows for listening and reading practice (P2) in this order, given that the tendency was that students firstly listened to their teacher reading the text and in a second stage they proceeded to read it themselves (Sánchez, 2009: 53, 61-62):

A.- Let us see; shall we take the express train

that leaves Southampton at 9.15 a. m.? We shall be

in London at 11.45. (lines 84-86).

The 'Exercises' are devoted to oral practice (P2) and consist of questions that are orally responded, which are once again very similar to Lado's question-and-answer drills. Some items are comprehension questions about the prior aural input (e.g., no. 2. 'What journey does Mr. A. propose to Mr. B?'), whilst other questions draw on the learners' personal opinion and preferences (e.g., no. 6: 'Does it give you pleasure to travel?'). These questions are closer to the creative nature of the P3 stage, even if proper production cannot strictly speaking be fully appreciated. Thus, the pedagogical sequence remains as P1-P2 alone.

${ }^{1}$ This is referred to as 'partially implicit' because on page 59 of this 'Travelling unit' there is a footnote suggesting that the teacher adds specific grammatical information. 


\subsubsection{The activity sequencing pattern from a cognitive perspective}

The cognitive pattern can globally be depicted as dec $\rightarrow$ pro with small letters. This indicates that the processes of declarativisation and proceduralisation are not fully complete. Declarative knowledge is not explicitly explained; it is rather 'incidentally' included in the text produced during the teacher-student conversation in 'Oral Introduction' and in 'Reading and Conversation'. Thus, full declarativisation $(D E C)$ is not to be expected, but dec. On the other hand, the quite restricted nature of the output practised in the 'Exercises' section does not allow for a neat P3; accordingly, students cannot attain complete proceduralisation and thus achieve automatisation; hence pro and not $P R O$.

Given that the listening work in the two first sections involves aural practice (P2), a certain level of proceduralisation (pro) can also be identified regarding this skill. Obviously, much more practice following this beginner level is needed to attain full proceduralisation in this respect.

\subsection{The Situational Language Teaching Method: Alexander, L.G. (1967a). First Things First. Student's Book}

\subsubsection{Topic and learning content of the unit}

The topic is past events. The specific linguistic points are divided into patterns and vocabulary. Patterns mainly focus on the past simple tense ('What's she's like?'; 'He (telephoned) four times/yesterday/yesterday morning/the day before yesterday/last night'; 'Did you/he/she/ etc.?'; 'Yes, (I) did'; 'No (I) did not/didn't'). The vocabulary is targeted at nouns (phone), adjectives (awful), verbs (answer, speak) and adverbs (again, points of time).

\subsubsection{The activity sequencing pattern from a pedagogical perspective}

Inductive methods typically begin with a pedagogically modelled text conditioned by the linguistic elements needed and which is representative of a habitual communicative situation; this is the case of the Situational Language Teaching Method as well, and so it appears in First Things First. Structural methods also include a limited set of activities of a varied nature, in which teacher and students engage in a rather artificial communicative process. The main aim is that students memorise the structures and vocabulary targeted by means of the continuous repetition supplied by the different drills implemented.

The first exercise of the first part is an 'aural/oral procedure'2. This comprises several listening exercises designed to exploit the pictures and corresponding dialogues on the first page of the unit. Similar to the 'Oral Introduction' in Berlitz's lesson, all these exercises involve an inductive and implicit P1 for the linguistic elements of the lesson that are introduced in the listening text and P2 for the receptive practice implied and the student's responses in the various drills performed.

${ }^{2}$ In Table 1 (section 5), the activities belonging to the first part will be preceded by $1(1.1 .-1.4)$ and those included in the second part will be preceded by 2 (2.5.-2.9). 
The second exercise is 'Comprehension questions' (with the books open), which focus on the patterns of each lesson. The answers to these questions require the understanding of the preceding aural text. In teaching unit 36 (Alexander, 1967b: 142), this exercise is aimed at eliciting Yes/No tag answers (e.g. Teacher: 'Is Ron Marston nice?'; Student: 'No, he isn't'); questions with who (e.g. Teacher: 'Who telephoned four times yesterday?'; Student: 'Ron Marston did'); negative and affirmative statements (Teacher: 'Did Ron Marston telephone three times yesterday?'; Student: 'He didn't telephone three times yesterday. He telephoned four times'); general questions with when, where, what, why, how many times, etc. Thus, comprehension questions would reflect $\mathrm{P} 2$ of the structures and vocabulary to be studied in the lesson.

The third group of activities consists of a pattern drill exercise with the books closed. The structural aim of this exercise is to elicit the construction 'What's he/she/it like? (It's) interesting'. Similar to the 'comprehension questions', this would entail P2. The final exercise in the first part of teaching unit 36 is a song (Oh, dear! What can the matter be?). Besides their contribution to the reinforcement of the previously learnt patterns, Alexander (1967b: xxii) recommends using songs, games and oral compositions in class due to motivational purposes. Accordingly, the song constitutes both receptive practice and further repetition and rehearsal for the language forms (P2).

The second part of teaching unit 36 starts with a pattern drill involving questions and answers. By means of several cues in the form of adverbs and time complements, students have to answer questions such as 'When did he phone?', which is responded as 'He telephoned last night', for example. Next comes a repetition drill. In chorus, group or individual modes, the students repeat certain patterns after their teacher with the help of the pictures from the second page of the lesson (see Appendix 2); for example:

Teacher: Look at the first picture. What did she do yesterday? All together!; Teacher and students: She aired the room. Teacher: All together! (Alexander, 1967b: 143. Italics in the original.)

Another pattern drill follows with new questions triggered by the previous pictures and drills as well as questions from the first part. The structures drilled range from short answers (Teacher: 'Look at the first picture. Did she clean her shoes/air the room?'; Student: 'No, she didn't/Yes, she did') to complete affirmative statements (e.g. Teacher (pointing at Monday). 'Look at the first picture. When did you air the room?'; Student: 'I aired it on Monday') and questions with when (e.g. Teacher: 'Look at the first picture. What did I do this morning?'; Student: 'I aired the room').

All the exercises in this second part, then, could be considered to embrace oral P2 for grammar and vocabulary.

The second part is closed written P2 of patterns and vocabulary via the dictation of the written 'Exercise' in the students' previous lesson 70 and an 'Exercise' located at the end of the unit on the second page. The 'Exercise' is the fourth pattern drill of the unit, and belongs to the drill type 'substitutions that force a change' (Lado, 1964: 97); e.g. from 'She is airing the room' to 'She aired it yesterday'.

Therefore, in the same way as in the Berlitz lesson, this Situational Language Teaching Method unit reflects a P1-P2 teaching sequence. 


\subsubsection{The activity sequencing pattern from a cognitive perspective}

As in the Berlitz's unit, dec $\rightarrow$ pro seems to be the underlying cognitive pattern. The sequencing of the activities begins with a series of dialogues, which entail a dec stage. At the same time, these dialogues are targeted at proceduralising the structures and lexis strategically included in them. This proceduralisation occurs in a primitive manner; hence pro instead of $P R O$. Therefore, it must be acknowledged that the $\mathrm{P} 1$ phase seeks proceduralisation from the very beginning, in such a way that the $d e c$ stage can be said to be somehow underrepresented or clearly subordinate to this pro phase. That is the reason why $D E C$, with capital letters, is not appreciated.

The rest of the activities in the unit belong to the pro phase, given that the practice is aimed at the proceduralisation of structures and vocabulary. However, a full $P R O$ stage is not attained, but only pro. This is due to two reasons. Firstly, despite the contextualisation supplied by the pictures, the drills are quite repetitive and mechanical in nature, contrary to communicative drills. Consequently, they either do not leave any space at all or a very small leeway for the establishment of form and meaning relationships (Sánchez and Criado, in press), which is an essential condition for full proceduralisation and automatisation (DeKeyser, 1998: 53; 2007b: 11). Secondly, similar to the Berlitz unit, a P3 activity that fully emphasises a 'transfer' stage (according to Sánchez, 1997: 168 and ff.; 2009: 78 and ff.) or 'exploitation/expansion phase' (Cook, 2001: 209) ${ }^{3}$ cannot be fully appreciated strictly speaking. Inductive methods abound in pro activities, and First Things First is not an exception.

\subsection{Oxenden, C. and Latham-Koenig, C. (2001). English File Upper Intermediate. Student's Book}

\subsubsection{Topic and learning content of the unit}

The topic of the unit is 'stories'. Regarding structures, narrative tenses are the focus of the lesson. The vocabulary area concerns verbs which are often confused by learners of English (wait/hope/expect, etc.). Regular and irregular past tense endings represent the pronunciation work. Lastly, the skills developed are listening 'actively' (reacting towards what interlocutors say); skimming and intensive reading; story telling and story writing.

\subsubsection{The activity sequencing pattern from a pedagogical perspective}

The lesson is divided into eight sections. Appendix 3 offers the first half of the initial section: 'Read Better' (page 38 from the textbook).

'Read Better' is devoted to skimming-, intensive- and pleasure- reading (pp. 38-39). It has two main functions: on the one hand, it acts as receptive practice itself (P2) -similar to the 'Oral Introduction' and the 'aural/oral procedure' in the Direct and Situational Language

${ }^{3}$ It should be noted that the meaning of 'transfer' is not located within SLA but within Foreign Language Teaching. It refers to the technique by which students are required to use the previously acquired language patterns and lexis in parallel contexts. 'Transfer' as a teaching strategy started to be applied in structurally based Methods (Sánchez, 2009: 78). 
Teaching Methods units respectively- and, on the other, as an implicit and inductive presentation (P1) of the narrative tenses, which appear contextualised in the text. The third and marginal function of this reading section is to introduce vocabulary in the first and last exercises of this reading set (P1). Narrative tenses are explicitly presented in the 'Focus on New Language' section (P1) by triggering, in this order, inductive and deductive learning: students firstly discover the rules themselves and confirm their hypotheses later with the rules provided. Then comes 'Practice' (P2) on p. 40, which mainly entails controlled, discrete-based manipulation of the narrative tenses in different exercises (cloze, sentence completion...). A mini-composition exercise appears at the end of this 'Practice' set (P3).

The fourth group of activities is 'Build your Vocabulary' (p. 41), which embraces the inductive presentation of lexicon and specially related controlled practice in isolated sentences (P1-P2). This vocabulary is not related to that introduced in the 'Read Better' section. Pronunciation work is then implemented with several repetition exercises and the categorisation of past tenses instances according to the right sound. Overall, this section comprises very controlled P2.

In the first exercise of the sixth part, 'Listen Better' (on p. 42), students retell the story simultaneously heard by all the class. Thus aural receptive and oral productive practice (P2) is included, since the gist of the story must be understood in order to reconstruct it. Also, the aural text serves as a contextualised presentation (P1) for the lexico-grammatical functions (expressing reaction to a story being told -surprise, agreement...) that are subsequently worked on in a discovery-learning exercise (P1) in the second listening exercise. Lastly, the students practise saying all the expressions with the right intonation (P2).

'Making conversation' (p. 42) is the seventh part. First of all students rehearse this skill by means of further retelling of two different passages (P2). Then comes the main objective of this section: the students' oral production of three stories (P3) from a list of given topics on the basis of several prompts. Finally, in the first exercise of the 'Write Better' section on p. 42, students undertake some preparatory work on story-telling composition by means of reading comprehension and style work (addition of adverbs to make a story more vivid). This accounts for a brief P1 in the case of the adverbs and P2 in reading comprehension. After planning their draft in the second exercise, the last and main activity of this concluding section demands that students write a 150 -word story (P3).

Therefore, and as opposed to Berlitz's and the Situational Language Teaching Method lessons, the general pedagogical sequencing pattern of this file corresponds to the PPP, i.e. P1P2-P3.

\subsubsection{The activity sequencing pattern from a cognitive perspective}

The activity sequencing can be basically represented as $D E C->P R O$ with certain nuances. In the first place, and similar to Berlitz's and First Things First unit, the reading text includes certain hints of proceduralisation (hence pro in small letters), in the sense of this skill being practised. The text itself provides some incipient (if any at all and most probably unconscious) beginning of declarativisation (dec) regarding the narrative tenses. This becomes an explicit process in the following section via the focus on form ('Focus on New Language'). The completion of this process and thus the establishment of $D E C$ in long-term memory take place in the 'Practice' exercises, together with the beginning of proceduralisation (pro). In such 
exercises, students manipulate forms in a highly controlled manner in the responses to questions, the completion of sentences and a cloze (Practice a, b, and c). The writing of the minicomposition (Practice d) strongly supports the activation of this proceduralisation process.

Declarative knowledge of vocabulary $(D E C)$ is fully achieved in the 'Build your Vocabulary' section thanks to the explicit focus on lexis and the controlled practice provided. Given that the lexis introduced in the 'Read Better' section is not worked upon with any practical exercises, only dec can be attained. In 'Better Pronunciation', the full proceduralisation of the phonemes underlying the correct pronunciation of the past tense (PRO) can be achieved by means of mechanical and discrete-item-based practical exercises (DeKeyser, 1998: 53).

In the same way as in the reading text, the listening extract in 'Listen Better' entails ongoing proceduralisation of this skill (pro), as well as the development of declarative knowledge and the beginning of proceduralisation concerning the functions or lexico-grammatical patterns focused on (DEC->pro).

The speaking task in 'Making Conversation' involves the definite proceduralisation and automatisation (PRO) of the narrative tenses, vocabulary (of the 'Better Vocabulary' section) and functions, as well as a solid reinforcement for the proceduralisation of the past tense pronunciation. Finally, the 'Write Better' section contributes to the automatisation of the narrative tenses and vocabulary $(P R O)$.

\section{Discussion OF RESUltS}

The following table synthesises the data analysed in section 4. Each activity from the three lessons is included in accordance with the P stage -from the PPP- and the cognitive phase -either $\operatorname{dec} / D E C$, pro/PRO- it refers to. 


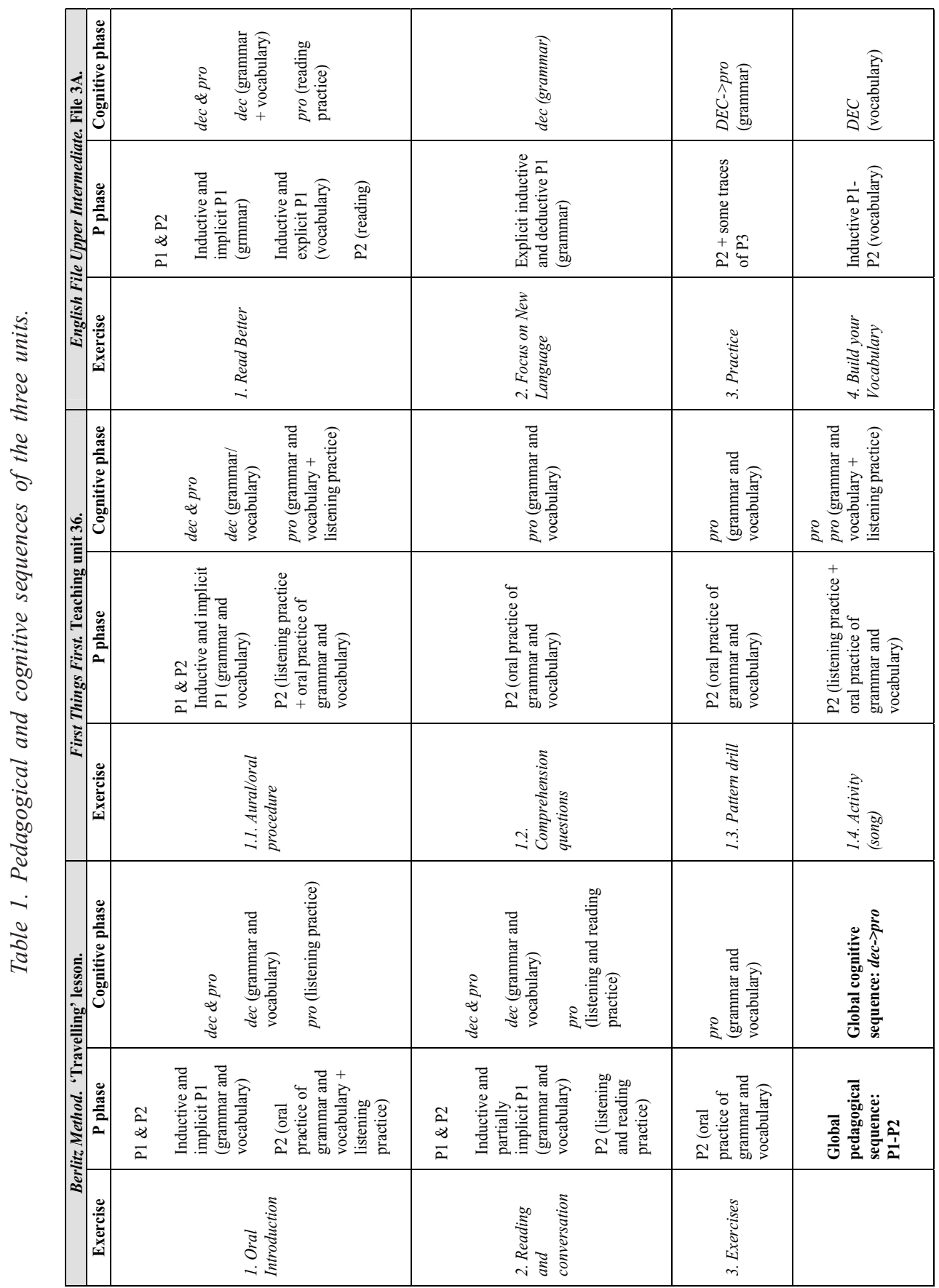




\begin{tabular}{|c|c|c|c|c|c|c|}
\hline 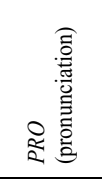 & 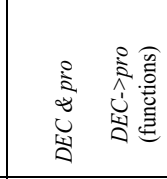 & 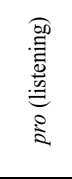 & 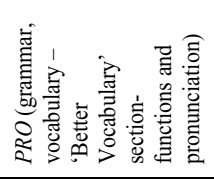 & 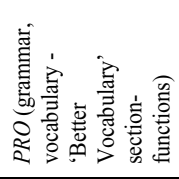 & 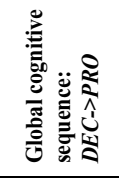 & \\
\hline 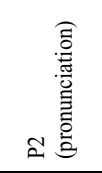 & 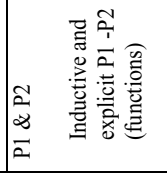 & 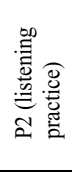 & 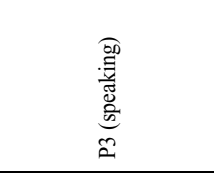 & 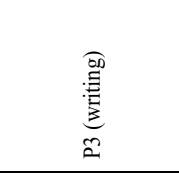 & 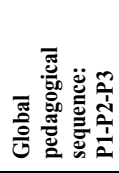 & \\
\hline 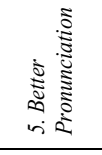 & 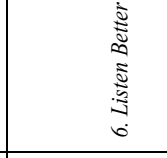 & & 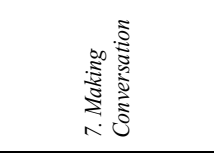 & 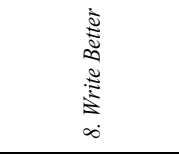 & & \\
\hline 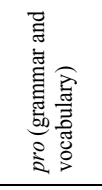 & 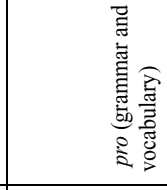 & & 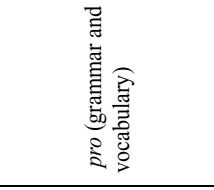 & 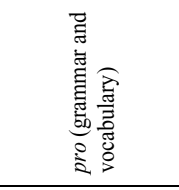 & 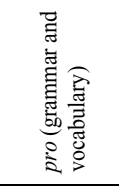 & 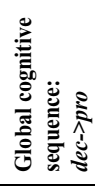 \\
\hline 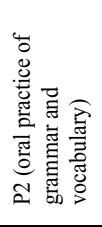 & 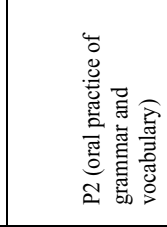 & & 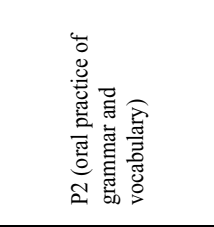 & 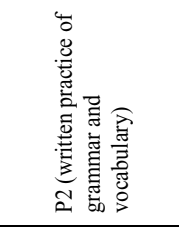 & 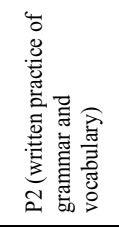 & 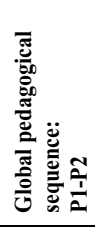 \\
\hline 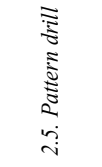 & 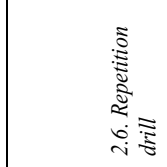 & & 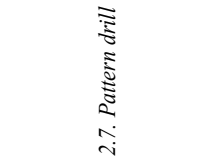 & 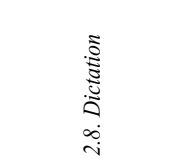 & 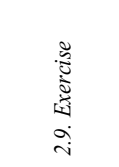 & \\
\hline
\end{tabular}


Although Berlitz's and Alexander's units belong to the beginner level and the English File textbook is aimed at an upper-intermediate level, the similarities between the two types of sequencing in the three units are remarkable. Indeed, the analysis carried out in section 4 shows how deep the PPP and the DEC->PRO models are built into the ELT materials, in spite of the different methodological options represented by the three textbooks. On the one hand, the sequences that underlie the three ELT textbooks as well as the three methods they adjust to are similar regarding the basic pattern of lesson organisation. The Presentation (P1) Practice (P2) - Production (P3) sequence can be appreciated in a linear distribution, despite the fact that P3 is absent in the oldest lessons (Berlitz's and Alexander's). This is most probably due to the elementary level of the textbooks. On the other hand, all such sequencing patterns generally comply with the basic tenets governing language acquisition fairly well, at least in the path or direction: dec $\rightarrow$ pro for Berlitz's and Alexander's lessons and DEC $\rightarrow P R O$ for the 2001 file.

At first glance, it appears that each book is significantly different in layout. Moreover, the methods to which each one of them subscribes add apparently convincing reasons to take such a belief for granted. Certainly, differences are obvious in some aspects of the activities designed; this is also the case if we pay attention to the amount and the variety of the activities found in each unit or lesson. Nevertheless, these divergent features should not mislead the reader. A careful analysis of the fundamental underlying patterns regarding the teaching sequencing reveals a low level of variation in the teaching and cognitive sequence, as the nature of the activities themselves evidences.

From a pedagogical perspective, the three lessons start presenting the language that the students are going to work with throughout the unit (presentation stage). Exercises for practice follow and a more free and final stage is offered to favour production in the case of English File Upper Intermediate. The fact that P1 and P2 take their turn during the three lessons somehow slightly disrupts the linearity of the PPP sequence. This is due to the inductive contextualised P1 in all the coursebooks materialised through the listening and reading texts, which entail not only $\mathrm{P} 1$ but also receptive practice (P2); that is the reason why there exists P1 in English File Upper Intermediate towards the middle and end of the file (in 'Build your Vocabulary' and 'Listen Better'). This scheme reveals that the pedagogical homogeneity of the units is broken down into further sub-blocks which maintain the same pedagogical sequence (P1-P2). But what is clear is that the order of the teaching stages in the two oldest units is P1 ${ }^{\circledR}$ P2; in the case of the 2001 lesson, these different P1 ${ }^{\circledR}$ P2 sub-blocks are each targeted at different types of content (grammar, vocabulary, pronunciation, functions), whose joint output production (P3) is finally triggered in 'Making Conversation' and 'Write Better'. Accordingly, the three lessons highly adhere to the linearity of the PPP; the only outstanding differences between Berlitz's and Alexander's units, on the one hand, and the English File Upper Intermediate lesson, on the other, are the aforementioned absence of P3 in the first two and the inclusion of explicit deductive P1 in the English File Upper Intermediate unit.

As mentioned above, the cognitive perspective reveals a similar organisation in the sequencing of the canonical stages: the 2001 textbook fulfils the expected $D E C \rightarrow P R O$ sequencing for adults in formal L2 learning situations, whilst Berlitz's and Alexander's units do not reach full declarativisation and proceduralisation but comply with the order of such processes prescribed in cognitive psychology: dec $\rightarrow$ pro. Especially in the Situational Language Teaching and Communicative Methods, there exists a meticulous selection of grammatical patterns and lexis, 
the goal of which is to unconsciously suggest the underlying logic of the linguistic system. This is achieved through the implicit and inductive presentation of the new language to be learnt, which neatly triggers an inductive mode of learning in the initial dialogue or text at the beginning of the three textbook units. The lexical and grammatical objectives are clearly included, carefully arranged by the textbook authors and suitably disguised within a pedagogically arranged situation.

Declarativisation of knowledge occurs in an apparently covert way in the Direct and Situational Language Teaching Methods -which I represent here as dec with small letters, in opposition to the $D E C$ of the 2001 lesson, when declarativisation is clear and complete. Proceduralisation of knowledge follows $\operatorname{dec} / D E C$ (depending on the unit), as can be appreciated in the table above in the 'Exercises' of the Berlitz Method, in nearly all the drills in the Situational Language Teaching Method and in the 'Practice', 'Listen Better', 'Making Conversation' and 'Write Better' sections from English File Upper Intermediate lesson. Also, as has already been indicated in section 4, and corresponding to their status as inductive methods, pro may be found in the Direct and Situational Language Teaching Methods from the very beginning of the lessons, but always together in close cooperation with dec. In other words, at the same time new language is presented, one may practise with it, which is the case of 'Oral Introduction' and 'Reading and Conversation' from the Berlitz unit, the 'aural/oral procedure' in the Situational Language Teaching Method; this also occurs in the 'Read Better' and 'Listen Better' sections in the 2001 lesson. This didactic situation with such types of activities is far from what one might find in natural language learning situations, where learners face direct practice and production $(P R O)$ without any previous pedagogical arrangement of the materials, and without any previous 'warning' on the grammatical difficulties or novelties one may find in the language used.

\section{Conclusion on the Sequencing patterns in the three teXtbooks}

On the basis of the preceding analysis, it can be concluded that (i) there is a strong correlation between the order of the pedagogical and cognitive sequences in the three lessons taken from coursebooks based on different ELT methods; (ii) in spite of the different methods, the three textbooks maintain significant similarities in the sequencing of the activities from the perspective of the PPP and the cognitive model; (iii) differences among methods are real, but they do not necessarily affect some basic procedures. The analysis here conducted suggests that the ELT methods examined may not affect some fundamentals of foreign language learning, since they hardly interfere with the key patterns governing knowledge acquisition. This final aspect of the conclusion suggests that the role of methods in the teaching/learning process may be more limited than it is generally assumed.

\section{REFERENCES}

Alexander, L.G. (1967a). First Things First. An Integrated Course for Beginners. Student's Book. London: Longman. 
Alexander, L.G. (1967b). First Things First. An Integrated Course for Beginners. Teacher's Book. London: Longman.

Anderson, J.R. (1982). "Acquisition of Cognitive Skill”, in Psychological Review, 89: 369-406.

Anderson, J.R. (1983). The Architecture of Cognition. Cambridge, MA: Harvard University Press.

Anderson, J. R. (1987). "Skill Acquisition: Compilation of Weak-Method Problem Solutions", in Psychological Review, 94, 2: 192-210.

Anderson, J.R. (2005). Cognitive Psychology and its Implications. ( $6^{\text {th }}$ ed). New York: Worth Publishers.

Anderson, J.R. and Lebiere, C. (1998). The Atomic Components of Thought. Mahwah, NJ: Erlbaum. Anderson, J.R., Bothell, D., Byrne, M.D., Douglass, S., Lebiere, C. and Qin, Y. (2004). “An Integrated Theory of the Mind", Psychological Review, 111: 1036-1060.

Berlitz, M.D. (1931). Berlitz Method for Teaching Modern Languages. English Part. First Book. (439 ${ }^{\text {th }}$ ed). London: Berlitz School.

Cook, V. (2001). Second Language Learning and Teaching. ( $3^{\text {rd }}$ ed.). London: Edward Arnold.

Criado, R. (2008). Patterns of Activity Sequencing in the Teaching of English as a Foreign Language and their Effects on Learning: A Quasi-Experimental Study. Dissertation. University of Murcia, Spain. http://www.tesisenred.net/TDR-1021108-094744/index_cs.html, accessed 3 March, 2009.

DeKeyser, R.M. (1998). "Beyond focus on form: Cognitive perspectives on learning and practicing second language grammar, in C. Doughty and J. Williams (eds.), Focus on Form in Classroom Second Language Acquisition. Cambridge: Cambridge University Press, 42-63.

DeKeyser, R.M. (2007a). "Skill acquisition theory", in B. van Patten and J. Williams (eds.), Theories in Second Language Acquisition. An introduction. Mahwah, N.J.: Lawrence Erlbaum Associates, 97-113.

DeKeyser, R.M. (2007b). "Introduction: Situating the concept of practice", in R.M. DeKeyser (ed.), Practice in a Second Language. Perspectives from Applied Linguistics and Cognitive Psychology. Cambridge: Cambridge University Press, 1-18.

DeKeyser, R.M. and Sokalski, K.J. (1996). "The differential role of comprehension and production practice", in Language Learning, 46, 4: 613-42.

Howatt, A.P.R. (1984). A History of English Language Teaching. Oxford: Oxford University Press.

Howatt, A.P.R. with Widdowson, H. G. (2004). A History of English Language Teaching. (2 ${ }^{\text {nd }}$ ed). Oxford: Oxford University Press.

Johnson, K. (1996). Language Teaching and Skill Learning. Oxford: Blackwell.

Johnson, K. (2008). An Introduction to Foreign Language Learning and Teaching. (2 ${ }^{\text {nd }}$ ed.). Harlow, Essex, London; New York: Longman.

Kelly, L.G. (1969). 25 Centuries of Language Teaching. New York: Newbury House Publishers. Lado, R. (1964). Language Teaching. A Scientific Approach. New York: McGraw Hill.

Lewis, M. (1996). "Implications of a lexical view of language", in D. Willis and J. Willis (eds.), Challenge and Change in Language Teaching. Oxford: Heinemann, 10-16.

Merriam-Webster Online Dictionary. "Sequence" and "sequencing" entries. URL: http:// www.merriam-webster.com/dictionary, accessed 3 July, 2007.

New Shorter English Dictionary (1997). CD-ROM. Oxford University Press and Electronic Publishing B. V. Rotherdam. The Netherlands.

O'Malley, J. M., Chamot, A. U. and Walker, C. (1987). "Some applications of cognitive theory to second language acquisition", in Studies in Second Language Acquisition, 9: 287-306.

Oxenden, C. and Latham-Koenig, C. (2001). English File Upper Intermediate. Student's Book. Oxford: Oxford University Press. 
Richards, J.C. and Rodgers, T.S. (2001). Approaches and Methods in Language Teaching. (2 ${ }^{\text {nd }}$ ed.). Cambridge: Cambridge University Press.

Sánchez, A. (1992). Historia de la enseñanza del español como lengua extranjera. Madrid: SGEL, S.A.

Sánchez, A. (1997). Los métodos en la enseñanza de idiomas. Evolución histórica y análisis didáctico. Madrid: SGEL, S.A.

Sánchez, A. (2004) Enseñanza y aprendizaje en la clase de idiomas. Madrid: SGEL, S.A.

Sánchez, A. (2009). La enseñanza de idiomas en los últimos cien años. Métodos y enfoques. Madrid: SGEL, S.A.

Sánchez, A. and Criado, R. (in press). "Cognitive underpinnings of repetitive practice in the learning of EFL". Proceedings of the XXVII AESLA International Conference. Ciudad Real, 2009.

Skehan, P. (1998). A Cognitive Approach to Language Learning. Oxford: Oxford University Press.

Ullman, M.T. (2004). "Contributions of Memory Circuits to Language: the Declarative / Procedural Model", in Cognition, 92: 231-270.

Willis, D. and Willis, J (2007). Doing Task-based Teaching. Oxford: Oxford University Press. 


\section{APPENDICES. Lessons from the three textbooks}

Appendix 1. Berlitz, M.D. (1931). Berlitz Method for Teaching Modern Languages. English Part. First Book. (439 ${ }^{\text {th }}$ ed). London: Berlitz School. 'Travelling lesson' (sample)

19. When will you return? 20. How many months will you remain absent? 21. Shall we see each other before you leave? 22. Where shall I see you? 23. At whar time will you call?

\section{Travelling \\ ORAL INTRODUCTION}

London is the capital of England. What is the name of the capital of France? of Germany? Paris is a large city. It is the largest city of France. Russia is a large country. What is the name of the largest city in Europe? What is the name of the largest city in America? Is Scotland north or south of England? Is Brighton north or south of London? What country is south of France? What country is north of Italy? Is Austria east or west of Germany?

Brooklyn is near New York. San Francisco is far from New York. Brighton is not far from London; it is only 50 or 60 miles from London. New York is far from London; more than 3000 miles. In England and America we measure distances by miles; in France, Italy, and other countries we calculate distances by kilometres. A mile is a little more than a kilometre and a half (1609 metres). What is the distance between London and Brighton? What is the distance between London and New York? What is the distance between Paris and Bordeaux? (363 miles).

If we go from one country to another, from one city to another, we travel. Do the English travel much? Do they travel more than the French? Do you travel during Summer? Are there many English travellers in Italy?

We can travel by railway (by train), by boat or by air. From Paris to Rome you go by train. From Southampton to New York we go by boat (in a steamer). If you trave! by rail, you make a journey. If you travel by boat, you make a voyage. How long does it take to go from Europe to America? About a week $(6,7$ or 8 days). How long does 


$$
-60-
$$

B. - 1 prefer you to call for me, as 1 have a great deal to do to get ready for the journey. must therefore leave you now. Oood-bye, see you tomorrow.

\section{EXERCISES}

1. Do you travel in Summer? 2. What journey does Mr. A. propose to Mr. B.? 3. Has Mr. B. ever been in London? 4. Are these gentlemen in England or on the Continent? 5. What does Mr. B. want to do before leaving England? 6. Does it give you pleasure to travel? 7. Does it give you pleasure to take a walk in fine weather? 8 . When do they wish to start? 9. Do you wish to take a lesson to-morrow? 10. Do you wish to have a great deal of money? 11. Do ladies wish for beautiful clothes? 12. Is Mr. B. willing to start the next day? 13. Are you willing to remain here two hours? 14. How long does Mr. B wish to stay in London? 15. Where does he wish to go afterwards? 16. Does Mr. A. like that idea? 17. Can they go to the Continent by train? 18. Is England surrounded by water? 19. Can we go to Australia by train? 20. Must we take a boat to go to England? 21. What do the English call the water between England and France? 22. Is it a pleasure to cross the Channel in fine weather? 23. Is it a pleasure during bad weather? 24. Which are the principal lines going from England to France? 25. Does it take a long time to cross from Dover to Calais? 26. How long does it take in fine weather? 27. Does $\mathrm{Mr}$. A. prefer the Dover-Calais route to the Newhaven-Dieppe one? 28. Why? 29. Is the sea calm when the weather is bad? 30. Is it pleasant to cross when the sea is rough? 31 . Where can you see at what time the trains

$$
-61-
$$

arrive and leave? 32. By what trains do you prefe to travel, by express trains or local trains? 33. Why 34. Do local trains stop very often? 35. At what time will Messrs. A. and B. start? 36. At what time will they arrive? 37. At what time will Mr. A. go to his friend's house next morning? 38. Does Mr. B. remain with Mr. A. or does he leave him? 39. Why does he leave him?

\section{The Departure \\ ORAL INTRODUCTION}

When you travel you take clothing with you. You put the clothing in trunks or boxes, in portmanteaux or bags. A trunk or a box is large; you cannot carry it. You can carry the portmanteau and the bags

I put my clothing into my trunk. I pack my trunk the servant (the porter) carries my trunk down

What do you put into your trunk? Do you carry your trunk yourself? Who carries it? What do you say to the porter?

I go to the rallway station. You do not walk to the station; you take a cab or a taxi. Do you go to the station on foot or do you drive there? Where do the trains arrive and leave? At what time does the train from - arrive? At what time does the train for - leave?

In the station there are different platforms. You ask from which plattorm the train for - - will leave. You ask if it is the train on the right or on the lefit. What questions do you ask at the station?

Before entering the railway carriage (in America: car) you get your tickets. You get your tickets at the booking office (in America: ticket office); you say: One first class to London. Two second class returns to Brighton. How much? (If you do not understand, you say: Will you 
Appendix 2. Alexander, L.G. (1967a). First Things First. An Integrated Course for Beginners. Student's Book. London: Longman. Teaching unit 36 (students' lessons 71 and 72). Full content

Lesson 71

JAN:: Whál's Rón Márston like, Páuline? PAULINE: He's áwful!

He télephoned me

fóur tímes yésterday,

and thrée times

the dáy befóre yésterday.

PaULINE: He télephoned the óffice •

yésterday mórning

and yésterday afternóon.

My bóss ánswered the télephone.

JANE: What did your bóss sáy to him?

Pauline: He sáid, "Miss White is týping léters. She cán't spéak to you nów?"

Pauline: Thén I arrived home at six o'clóck yesterday évening. He télephoned agáin. But I didn’t ánswer the phóne!

JaNE: Díd he télephone again lást night? Pauline: Yés, he did.

He telephoned at nine o'clóck.

JANE: Whát did you sáy to him?

Pauline: I saiid, "This is Páuline's móther.

Pléase dón't télephone my dáughter agáin!"

JANE: Did he télephone agáin? PAULINE: Nó, he didn't!
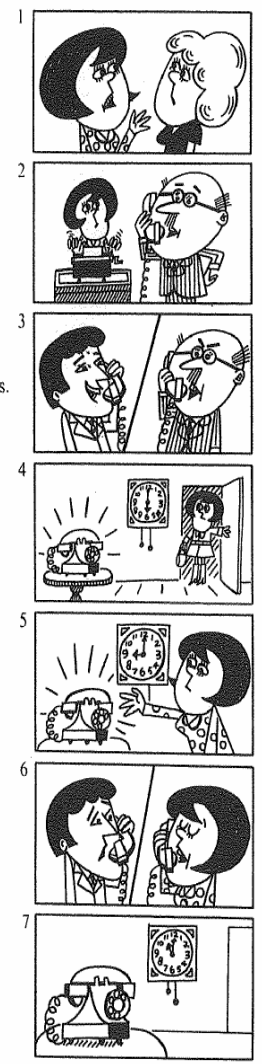

Lesson 72

\begin{tabular}{|c|c|c|}
\hline $\begin{array}{l}\text { TODAY } \\
\text { this morning }\end{array}$ & $\begin{array}{l}\text { YESTERDAY } \\
\text { ycsterdily morning }\end{array}$ & $\begin{array}{l}\text { THE DAY BEFORE YESTERDAY } \\
\text { the dily before yesterday } \\
\text { in the morning }\end{array}$ \\
\hline this afternoon & yesterdily aftemoon & $\begin{array}{l}\text { the daly before yesterday } \\
\text { in the afternoon }\end{array}$ \\
\hline this evening & yesterdily cvening & $\begin{array}{l}\text { the day before yesterdayy } \\
\text { in the evening }\end{array}$ \\
\hline tonight & lists night & the night before last \\
\hline
\end{tabular}

When did you ...?
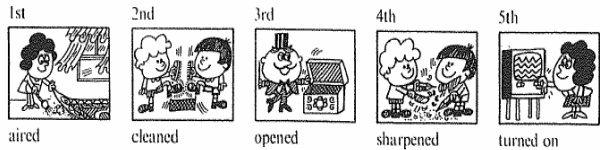

6(1)
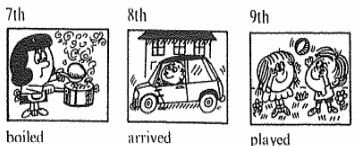

turned on

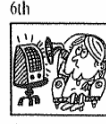

listened

boiled
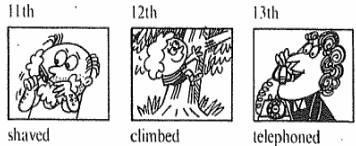

played

1011
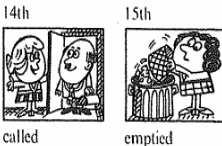

Exercise

Look at this:

She is airing the room now. She ... it yesterday.

She aired if yestercley.

Do these in the same was.

It is raining now. It ... yesterday.

It is snowing now. It . . . yesterday.

She is boiling some eggs. She ... some yesterday.

We are enjoying our lunch. We ... il yesterday. to

They are hurrying to work. They ... to work yesterday, too. 
Appendix 3. Oxenden, C. and Latham-Koenig, C. (2001). English File Upper Intermediate. Student's Book. Oxford: Oxford University Press. File 3A (sample)
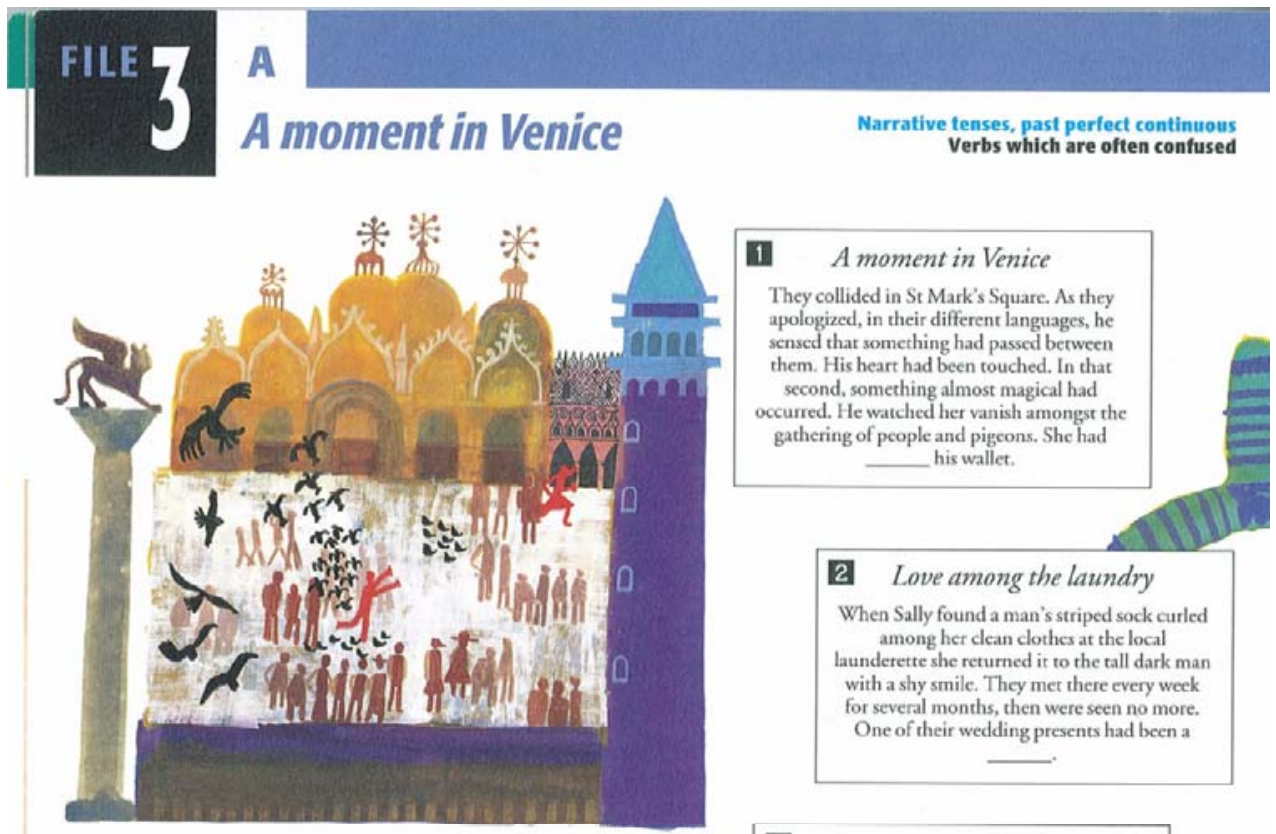

1 A moment in Venice

They collided in St Mark's Square. As they apologized, in their different languages, he sensed that something had passed berween them. His heart had been touched. In that second, something almost magical had occurred. He watched her vanish amongst the gathering of people and pigeons. She had his wallet.

\section{READ BETTER}

Intensive reading

a Look at the list. Underline what you read in your own language.Circlewhat you read in English. Compare with a partner. How much time do you spend reading in English a week?

national papers sports papers novels short stories poetry textbooks academic articles the Internet magazines song lyrics 'Graded Readers'

b Quickly read the introduction.

1 What is the mini saga competition?

2 Whose idea was it? What made him think of it?

3 What are the rules?

Since 1988 the Telegroph newspaper has organized a 'mini saga' competition. A mini saga is a very short story and it was invented by the well-known science-fiction writer Brian Aldiss. He was working on a very long novel at the time (three volumes) and he suddenly had the idea that it might be fun, as a complete contrast, to try to tell a whole story in just 50 words. The rules of the competition are simple. The text must be 50 words exactly, and it must tell a story. The best stories are published yearly in book form.

c Read each mini saga intensively (slowly and carefully) with the glossary. Guess the missing words.

\section{(3. Revenge is sweet}

They had been arguing bitterly the night before. He had come in from the garage with oil on his shoes. Fed up, desperate, she stabbed him. Horrified at what she had done, she drove away from the house along the cliff road. Suddenly she realized that the brakes weren't
4 Like mother, like son

1955

Dear Mummy

I hate this boarding school. Food awful, prefects bully me. Please take me home. Love, David.

Dear David

Nonsense! Chin up.

Mother

1997

Dear David

I hate this home. Food awful, nurses treat me like a child. Fetch me immediately. Mother

Dear Mother

! Chin up. 